Tendinopathies

\section{Understanding tendinopathies}

\section{G A Murrell}

\section{Is apoptosis the heart of the problem?}

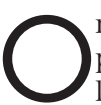
ne of the "banes" of most health professionals who look after athletes and workers is tendinopathies. What causes them? What gets them better? Recently there have been several advances that may contribute to our understanding of these disorders.

We all know that tendinopathies occur in the tendinous portion of musculotendinous units that cross joints, often two joints-for example, the extensor carpi radialis brevis in tennis elbow, the patellar tendon in jumpers knee-and that they occur in situations of repetitive, high, often eccentric loading. The classic pathology is a loss of the normal collagenous architecture and replacement with an amorphous mucinous material that lacks the parallel, longitudinal architecture of normal tendon. Soslowsky et $a^{2}$ made a major advance when they developed an animal model that could reproduce many of the microscopic changes of supraspinatus tendinopathy. The model involved running rats on a treadmill for up to an hour a day for 4-16 weeks. Supraspinatus tendons in the exercised animals had an increase in cellularity and loss of their normal collagen fibre organisation. The tendons were larger than normal in cross sectional area and had deteriorated mechanical properties. Specifically, they had a decreased modulus of elasticity and a decreased maximum stress at failure.

If over-exercise is so important, then the next question is how stress translates into these degenerative changes? Arnoczky et $\mathrm{al}^{3} 4$ have recently shown in cultured canine patellar tendon cells that there is a direct relation between the amount of stress the tendon cells see and the induction of a stress activated protein kinase (c-Jun $\mathrm{N}$-terminal kinase $(\mathrm{JNK}))$. Cyclic strain resulted in an immediate activation of JNK, which peaked at 30 minutes. This activation was regulated by a magnitude dependent, but not frequency dependent, calcium dependent mechanotransduction pathway. Whereas transient JNK activation is associated with normal cell processes, persistent JNK activation has been linked to the initiation of apoptosis-or programmed cell death. ${ }^{5}$

This work links nicely with some of our recent work, ${ }^{67}$ which shows that there is indeed increased apoptosis or programmed cell death in human rotator cuff tendons with tendinopathy. We

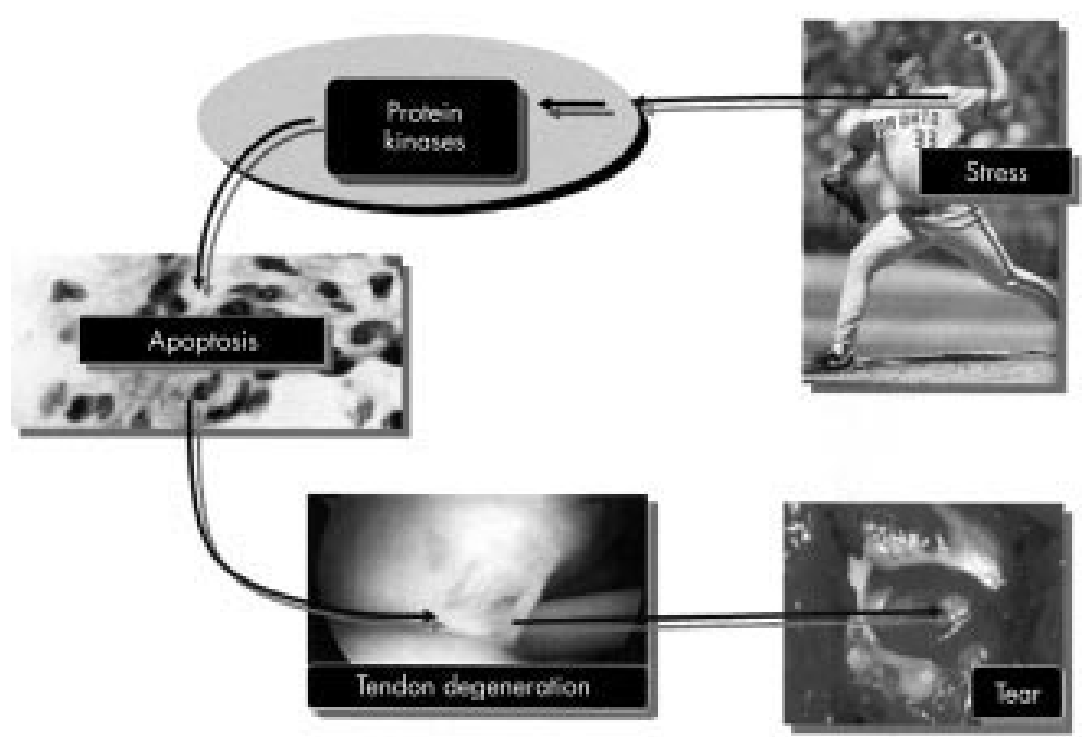

Figure 1 A schematic representation of how tendinopathies may arise. An increase in the amount and duration of load that a tendon cell experiences may result in activation of protein kinases, which when persistently activated cause the tendon cells to undergo apoptosis (programmed cell death). Increased cell death results in poor collagen synthesis and matrix remodelling and a collagenous matrix that is weaker and more prone to tearing. With time, this tendon may rupture. compared apoptosis by using the TUNEL and DNA laddering techniques in the edges of torn rotator cuff supraspinatus tendons removed at surgery with normal appearing samples of subscapularis tendons also taken at surgery. There was a threefold increase in apoptosis in torn tendinopathic rotator cuff tendon compared with the control tendon. The proportion of cells undergoing apoptosis increased with age and was also greater in the "normal" subscapularis tendons of patients with torn rotator cuff tendons compared with subscapularis tendons of patients with intact supraspinatus tendons.

\section{"... there is indeed increased apoptosis or programmed cell death in human rotator cuff tendons with tendinopathy"}

We can hypothesise therefore that tendinopathy may follow a pathway illustrated in fig l. An increase in the amount and duration of load that a tendon cell sees may result in activation of intracellular stress activated protein kinases, which when persistently activated cause the tendon cells to undergo apoptosis or programmed cell death. Increased cell death results in a collagenous matrix which is weaker and more prone to tearing. With time, this tendon may rupture.

Clearly, there are many details to insert into this pathway but there is hope that if we can flesh out the fine details of the pathway, then we may be able to develop strategies to break the cycle at one or more points and prevent and/or treat tendinopathy more effectively.

\section{ACKNOWLEDGEMENTS}

This work was supported in part by South Eastern Sydney Area Health Service/St George Hospital and NiCox Corporation. Br J Sports Med 2002;36:392-393

\section{Author's affiliation}

G A Murrell, Orthopaedic Research Institute, St George Hospital, University of New South Wales, Sydney, Australia

Correspondence to: Professor Murrell, Research and Education Center, 4-10 South St, Kogarah, Sydney, NSW 2217, Australia;

admin@ori.org.au

\section{REFERENCES}

1 Khan KM, Cook JL, Bonar F, et al. Histopathology of common tendinopathies. Update and implications for clinical management. Sports Med 1999;27:393408 .

2 Soslowsky LJ, Thomopoulos S, Tun S, et al. Neer Award 1999. Overuse activity injures the supraspinatus tendon in an animal model: a histologic and biomechanical study. Shoulder Elbow Surg 2000;9:79-84

3 Arnoczky S, Tiam T, Schuler P, et al. Upregulation of stress-activated protein kinases (SAPK) in response to increased 
cystolic calcium levels due to cyclic strain: a potential cellular mechnaism for repetitive stress injuries in tendons. In: 47th Annual Meeting, Orthopaedic Research Society; 2001 February 25-28; San Francisco. 2001:0020

4 Arnoczky SP, Tiam T, Lavagnino $M$, et al. Activation of stress-activated protein kinases
(SAPK) in tendon cells following cyclic strain: the effects of strain frequency, strain magnitude, and cytosolic calcium. J Orthop Res 2002; in press.

5 Wisdom R, Johnson RS, Moore C. c-Jun

regulates cell cycle progression and apoptosis by distinct mechanisms. EMBO J

1999; 18: 188-97.
6 Yuan J, Murrell G, Wei A-Q, et al. Apoptosis in rotator cuff tendonopathy. In: 47th Annual Meeting, Orthopaedic Research Society; 2001 February 25-28; San Francisco. 2001:0115.

7 Yuan J, Murrell GAC, Wei A-Q, et al. Apoptosis in rotator cuff tendonopathy. $J$ Orthop Res 2002:in press.

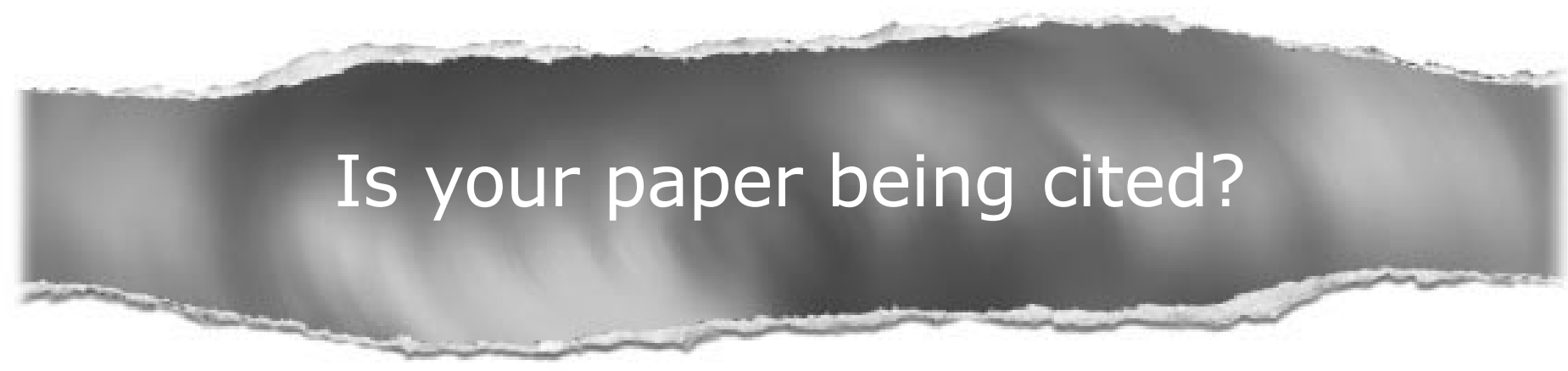

\section{CiteTrack service}

CiteTrack will alert you by email whenever new content in the British Journal of Sports Medicine or a participating journal is published that matches criteria you want to track

Topics: Tell CiteTrack which words or subjects to watch for in new content Authors: Be alerted whenever key authors you are following publish a new paper Articles: Know whenever a paper of interest to you is referenced by another paper

www.bjsportmed.com 
Boxing

\section{Safety measures in amateur boxing}

P Jako

\section{Amateur boxing has become one of the safest contact sports}

"It must be satisfactory to all true lovers of the Art, as a national and progressive institution, to feel that the past few years have witnessed changes-mostly in the right direction-in the science of Boxing." This was written by Allanson-Winn in $1897 .^{\prime}$ Since then, more than 1200 articles have been published on medical and ethical aspects of boxing, usually not differentiating between amateur and professional. Most of the studies have methodological problems: few cases were analysed; there was a lack of adequate controls; in many studies the boxers were about 60 years old and were boxing before safety rules and careful medical supervision had been introduced; the authors could not distinguish between the late impact of the blows and the effects of the ageing process or other factors, such as alcohol consumption, that produce similar clinical and morphological changes in the brain.

During the last two decades, amateur and professional boxing have become completely separate. The main differences are as follows.

- Amateur boxing uses the same set of rules world wide, whereas professional boxing has different sets of rules.

- In amateur boxing the main objective is to score points, and the knockout or knockdown is a byproduct. In professional boxing knockout and/or knockdown is an objective.

- In amateur boxing the wearing of a headguard is mandatory, whereas in professional boxing the use of a headguard is prohibited.

- In amateur boxing the ringside doctor may suspend the action at any point to examine the boxer and his decision to stop or continue a bout is binding, whereas in professional boxing this rarely happens.

- In amateur boxing if a boxer is "down" and fails to resume boxing within 10 seconds $(\mathrm{KO})$ or if a boxer is unfit to continue having received several hard blows to the head (RSC-H), he is not allowed to compete or workout in the gym for a specified period of time (at least four weeks). In professional boxing, in theory this is done but not in all cases. $^{2}$ The medical commission of the
International Amateur Boxing Association (AIBA) recorded the statistics of five Olympic Games and eight World Championships between 1980 and 1999 (4043 boxers, 3887 bouts). In 1980 at the Olympic Games, 11\% of bouts ended in $\mathrm{KO}$ and $6.4 \%$ in RSC-H, and bouts were stopped because of injury (mostly to facial areas) in $12.2 \%$. At the World Championships in 1999, the equivalent values were $0.3 \%, 1.5 \%$, and $0.3 \%{ }^{3}$

\section{HOW DID AMATEUR BOXING BECOME SAFER SO THAT TODAY IT IS NO MORE DANGEROUS THAN ANY OTHER CONTACT SPORT?}

The main reasons are:

- very careful medical control;

- use of protective equipment;

- improved refereeing;

- new AIBA regulations;

- sophisticated diagnostic imaging and neuropsychological tests.

All novice boxers undergo a comprehensive medical evaluation, including ophthalmic examination, resting electrocardiogram, and laboratory tests. The medical examination is repeated annually. The results are recorded in the boxer's record book. No boxer is allowed to compete at any tournament without the production of his/her record book. The AIBA medical handbook contains a list of pathological findings that preclude a person from becoming a boxer.

During a tournament, on the day of the bout the ringside doctor carries out a physical examination before the competition to ensure that the boxer is fully fit to box. This medical check up is also recorded in the boxer's record book.

During the bout, the ringside doctor has the right to stop the bout for medical reasons. In the case of a knockout, the management follows the guidelines of the Medical handbook of amateur boxing. If there is transient confusion, no loss of consciousness, and the symptoms resolve in 15 minutes (grade I), the doctor should perform a thorough medical examination to determine the need and nature of further medical observation or hospital admission. If the concussion symptoms last for 15 minutes, but there is no loss of consciousness (grade II), after a medical examination the boxer is taken to hospital for a neurological examination and computed tomography. If there is any loss of consciousness, either brief (seconds) or prolonged (minutes), the boxer is immediately transferred to the nearest emergency department by ambulance. Return to boxing depends on the severity of the concussion, but a 28 day rest period is the minimum. Before a boxer is allowed to fight again, he must be passed fit by a neurologist, after examinations by computed tomography or magnetic resonance imaging (MRI). The decision of the neurologist is recorded in the boxer's record book.

Repetitive concussion or subconcussive blows to the brain may lead to chronic traumatic brain injury. ${ }^{4} \mathrm{Al}-$ though studies indicate that amateur boxers do not exhibit any particular signs of neuropsychological ${ }^{5}$ or cerebral blood flow dysfunction, ${ }^{6}$ to minimise the risk of this, after repeated $\mathrm{KO}$ or RSC-H the rest period is one year or even enforced retirement.

It is debatable whether headguards diminish the impact of a blow, but it is indisputable that, since their mandatory use in amateur boxing, the rate of facial injuries has dramatically diminished.

In amateur boxing the referees watch the athletes more closely than in many other contact sports, and they stop the bout immediately if a boxer is unfit to continue. The increasing rate of RSC (referee stopping the contest) indicates the increased control in the ring.

The modifications of the AIBA rules over the last two decades based on medical considerations have served to protect the boxers. ${ }^{3}$

The importance of MRI in the early detection of sport related head injuries is well known. In the future new techniques (SPECT, functional MRI) should provide more insights into the pathophysiolgical and functional sequelae of injuries. $^{7}$

Neuropsychological testing is a promising tool in the early detection of any deterioration in neurocognitive status. ${ }^{8}$ If a brief, standardised method of neuropsychological testing applicable for worldwide use should become available, it should be introduced as part of the annual medical examination of boxers.

This is not an official statement of the AIBA but is based on AIBA articles and rules and on the recommendations of the AIBA medical handbook (2000).

Br J Sports Med 2002;36:394-395

\section{Author's affiliation}

P Jako, International amateur Boxing Association (AIBA), Veress Palne u 33, 1053 Budapest, Hungary 
Correspondence to Dr Jako

jako.aiba@matavnet.hu

\section{REFERENCES}

1 Allanson-Winn RG. Boxing. London: AD Innes and Co, 1897.

2 Cantu RC. Boxing and medicine. Champaign, IL: Human Kinetics, 1995:11-16.
3 Jako $P$. Modifications of the rules in amateu boxing and their effect reflected in the statistics of Olympic Games and World Championships. Hungarian Review of Sports Medicine 2000; LXI: 173-81.

4 Rabadi MH, Jordan BD. The cumulative effect of repetitive concussion in sports. Clin J Sport Med 2001;11:194-8.

5 Butler RJ. Neuropsychological investigation of amateur boxers. Br J Sports Med 1994;28:187-90.
6 Rodriguez G, Vitali P, Nobili F. Long-term effects boxing and judo: choking on brain function. Ital J Neurol Sci 1998;19:367-72.

7 Johnston KM, Ptito A, Chankowsky J, et al. New frontiers in diagnostic imaging in concussive head injury. Clin J Sport Med 2001;11:166-75.

$8 \mathrm{McCrea}$ M. Standardized mental status assesment of sport concussion. Clin J Sport Med 2001;11:176-81.

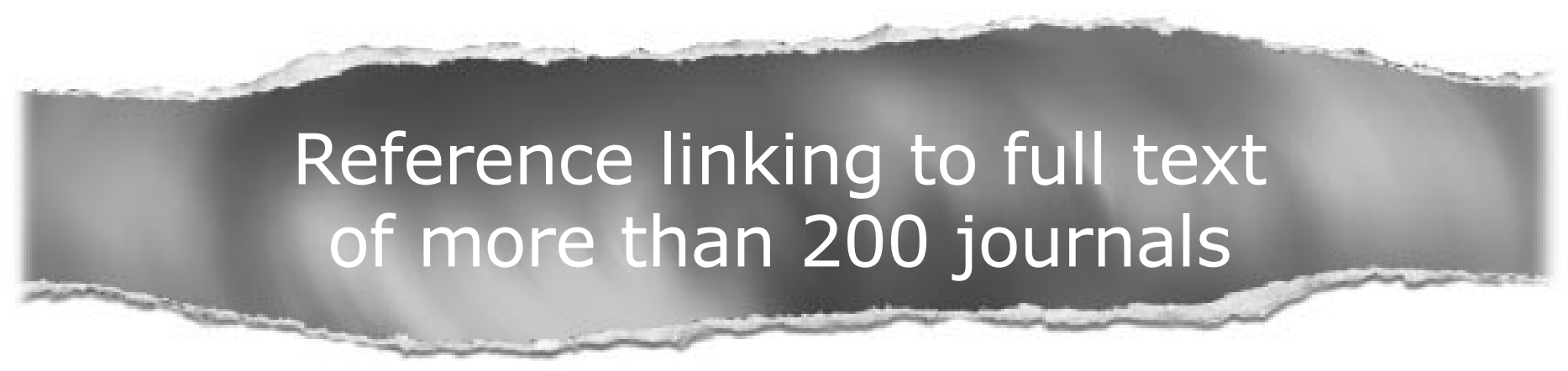

Toll free links

You can access the FULL TEXT of articles cited in the British Journal of Sports Medicine online if the citation is to one of the more than 200 journals hosted by HighWire (http://highwire.stanford.edu) without a subscription to that journal.

There are also direct links from references to the Medline abstract for other titles.

www.bjsportmed.com 